INT. J. REMOTE SENSING, 1999, VOL. 20, NO. 15 \& 16, 3051-3071

\title{
Remote monitoring of Mount Erebus Volcano, Antarctica, using Polar Orbiters: Progress and Prospects
}

\author{
A. J. L. HARRIS $\dagger$, R. WRIGHT \\ Department of Earth Sciences, The Open University, Milton Keynes \\ MK7 6AA, England, UK \\ and L. P. FLYNN \\ HIGP/SOEST, University of Hawai'i, 2525 Correa Road, Honolulu, HI 96822 , \\ USA
}

\begin{abstract}
Mount Erebus (Antarctica) is a remote and inhospitable volcano, where field campaigns are possible only during the austral summer. In addition to continuously monitoring seismic instruments and video cameras, data from scanners flown aboard polar orbiting space-craft, such as the Thematic Mapper (TM) and Advanced Very High Resolution Radiometer (AVHRR), can contribute to continuous, year-round monitoring of this volcano. Together these data allow measurement of the temperature of, thermal and gas flux from, and mass flux to a persistently active lava lake at Erebus' summit. The monitoring potential of such polar-orbiting instruments is enhanced by the poleward convergence of sub-spacecraft ground-tracks at the Erebus latitudes, permitting more frequent return periods than at the equator.

Ground-based observations show that the Erebus lava lake was active with an area of $\sim 2800 \mathrm{~m}^{2}$ and sulphur dioxide $\left(\mathrm{SO}_{2}\right)$ flux of $(230 \pm 90) \mathrm{td}^{-1}$ prior to September 1984. AVHRR-based lake area and $\mathrm{SO}_{2}$ flux estimates are in good agreement with these measurements, giving $(2320 \pm 1200) \mathrm{m}^{2}$ and $(190 \pm 100)$ $\mathrm{t} \mathrm{d}^{-1}$, respectively, during 1980. However during late-1984 the lava lake became buried, with TM data showing re-establishment of the lake, with a TM-derived surface temperature of $578-903^{\circ} \mathrm{C}$, by January 1985 . Following these events, ground-based lake area and $\mathrm{SO}_{2}$ flux measurements show that the lake area and $\mathrm{SO}_{2}$ flux was lower $\left(180-630 \mathrm{~m}^{2}\right.$ and 9-91 $\mathrm{td}^{-1}$, respectively). This is matched by a decline in the AVHRR- and TM-derived rate of magma supply to the lake from $330 \pm 167 \mathrm{~kg} \mathrm{~s}^{-1}$ prior to 1984 to $30-76 \mathrm{~kg} \mathrm{~s}^{-1}$ thereafter. Clearly, a reduction in magma supply to, and activity at, the lava lake occurred during 1984.

We look forward to using data from such future polar-orbiting sensors as the Moderate Resolution Imaging Spectrometer (MODIS), Advanced Spaceborne Thermal Emission and Reflectance Radiometer (ASTER), Enhanced Thematic Mapper (ETM+) and Advanced Along Track Scanning Radiometer (AASTR) to contribute to high ( $>$ once a day) temporal resolution measurement and monitoring of activity at this volcano. Such analyses will in turn contribute to a more complete understanding of how this volcano works.
\end{abstract}

†To whom correspondence should be addressed: HIGP/SOEST, University of Hawai'i, 2525 Correa Road, Honolulu, HI 96822, USA; e-mail: a.j.l.harris@open.ac.uk

Paper presented at the Fifth Circumpolar Remote Sensing Symposium held at the University of Dundee, Scotland, 22-25 June 1998. 


\section{Introduction}

Erebus has been continuously active ever since an active lava lake was first sighted on the summit crater floor of Mount Erebus volcano (Ross Island, Antarctica, figure 1) during the early 1970s (Giggenbach et al. 1973). Activity is typified by the persistence of a convecting lake of anorthoclase phonolite magma; the degassing of which feeds a plume of acid volcanic gases and aerosols (Kyle et al. 1990, 1994), and explosive strombolian eruptions (figure 2). This persistent lava lake activity is important for two reasons. Firstly, because the lava lake can be regarded as the upper surface of the volcano's plumbing system, the lake provides a window into this system. Analyses of the heat and gas emitted from this lake, and of bombs ejected from it, can provide important clues as to how this and other persistently active volcanic systems operate and erupt (e.g. Caldwell and Kyle 1994, Dunbar et al. 1994, Harris et al. 1999). Secondly, Erebus' volcanic plume has an impact on

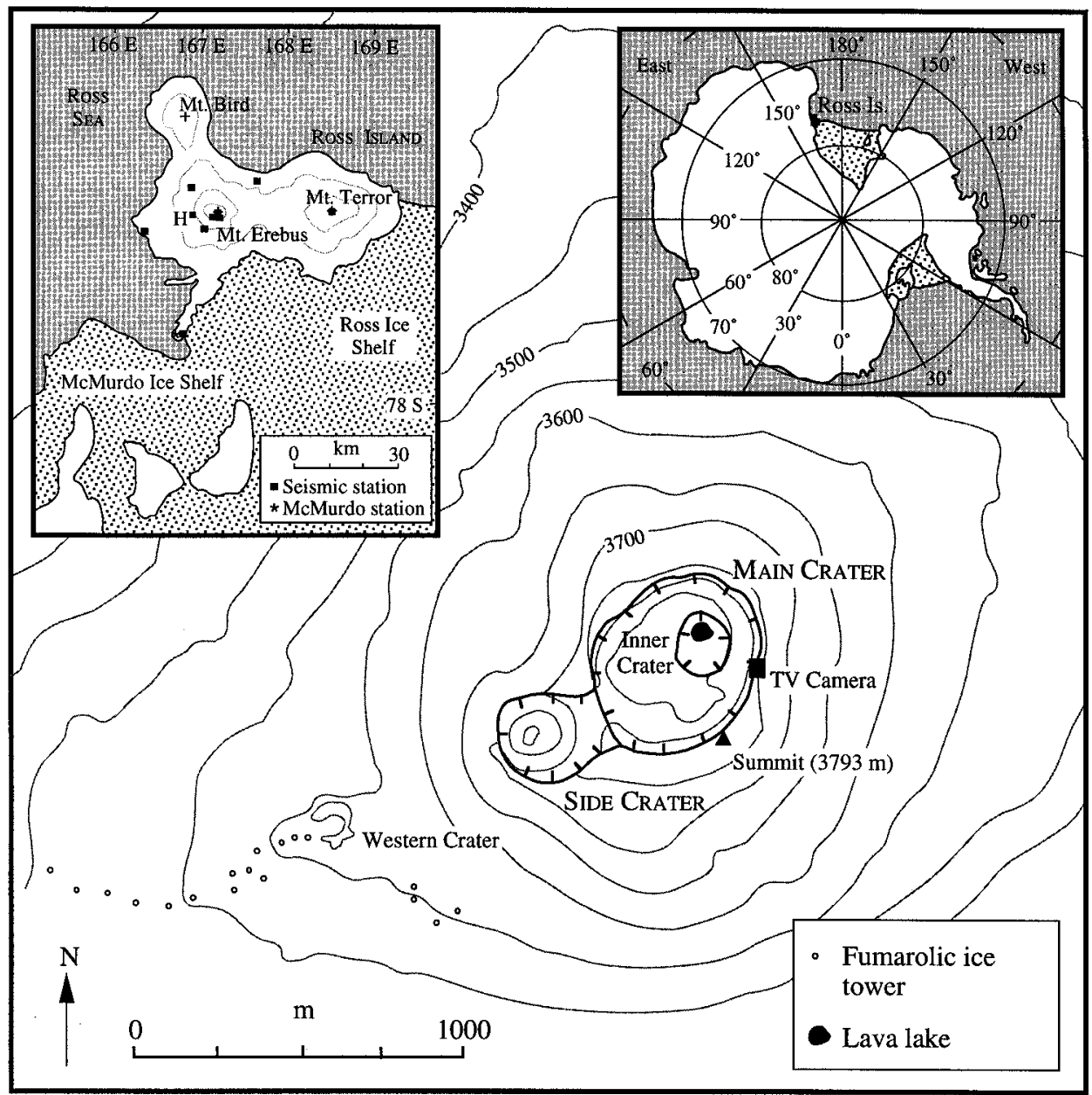

Figure 1. Map of the Erebus summit crater area after Otway et al. (1994) and Dibble et al. (1994a). Inset left is a map of Erebus and Ross Island showing the location of the radio-telemetered seismic network given by Kienle et al. (1984) and Kaminuma (1994), and inset right is a map of Antarctica showing the location of Erebus/Ross Island. 
the Antarctic environment, where Erebus may be an important contributor of aerosols and gases to the Antarctic atmosphere. Aerosols from Erebus have been traced at an altitude of $8 \mathrm{~km}$ above the South Pole (Chuan 1994) as well as in snow and ice samples across Antarctica (Palais et al. 1994, Zreda-Gostynska et al. 1997), and it has been estimated that Erebus may account for $10 \%$ of the Antarctic sulphur budget (Kyle et al. 1994) and 80\% of excess chlorine at the South Pole (Zreda-Gostynska et al. 1997). Monitoring Erebus' emissions is therefore important if (1) the environmental impact of Erebus is to be assessed and (2) the anthropogenic input to the Antarctic atmosphere is to be isolated and understood.

Many monitoring and measurement techniques that require field campaigns are confined to the austral summer (October-January) at this remote and inhospitable volcano. As a result sulphur dioxide $\left(\mathrm{SO}_{2}\right)$ and other gas/aerosol fluxes, for example, are typically only measured during December (e.g. Chuan 1994, Kyle et al. 1994, Sheppard et al. 1994) and are assumed to be representative of the whole year (Kyle et al. 1994). However, activity has been monitored all year round using seismic networks and TV cameras positioned around the volcano (e.g. Kienle et al. 1982, Dibble et al. 1994b, Kaminuma 1994; figure 1). Thermal data from sensors flown aboard polar-orbiting platforms, such as the Advanced Very High Resolution Radiometer (AVHRR) and Thematic Mapper (TM), are also capable of providing data during periods when the summit crater is inaccessible. Such data not only contribute to a more robust monitoring effort, but also to a more comprehensive understanding of how Erebus operates.

In the short time since Rothery and Oppenheimer (1994) reviewed the potential of satellite remote sensing for monitoring Erebus, a number of advances have been made in the techniques applied to measure and monitor volcanic activity using satellite-based thermal data. Further, the launch of the Earth Observing System (EOS) will greatly increase the quantity and quality of remotely sensed thermal data available for monitoring and understanding this and other volcanoes. Here we review the capabilities of remotely sensed thermal data for measuring, monitoring and understanding the Erebus system on the eve of the EOS era, and discuss the potential of the new data promised by the launch of EOS and other platforms.

\section{Progress}

\subsection{High spatial resolution data: the Thematic Mapper}

TM images of Erebus acquired during January 1985 and 1989 show that the lava lake is evident as a thermal anomaly in bands $5(1.55-1.75 \mu \mathrm{m})$, $6(10.42-12.42 \mu \mathrm{m})$ and $7(2.08-2.35 \mu \mathrm{m}$; figure 3$)$. The thermal structure of the anomaly on the 1985 image: a hot, highly radiant central area (yellow pixels) surrounded by a ring of cooler, less radiant (red) pixels, was originally interpreted by Rothery et al. (1988) as a result of the lake being surrounded by freshly erupted spatter. It was hypothesized that this spatter was ejected during a strombolian eruption evident from seismic records just 5 minutes before image acquisition (Rothery et al. 1988, Rothery and Francis 1990). Doubt has since been cast on this interpretation and it seems more likely that the warm 'halo' is the result of blurring due to forward scattering of radiation by the atmosphere and/or cross-sensor contamination (Rothery and Oppenheimer 1994). This latter argument is supported by an identical thermal structure on the January 1989 image (figure 3).

Whatever the cause of the halo, that the existence of an active lava can be confirmed from thermal anomalies evident in such imagery (figure 3 ) is an important 
observation for volcano monitoring. During September 1984 an increase in the size and frequency of strombolian eruptions buried the lake (Caldwell and Kyle 1994). Although a 'small lava pool' was observed periodically in late December 1984, no further ground observations were possible until the 1985-1986 austral field season, by which time a 15-m diameter lake had re-established itself (Kyle 1986, Rowe and Kienle 1986). The observation of the intense thermal anomaly in the TM data during January 1985 suggests that the lava lake had re-established itself by early 1985 (Rothery et al. 1988). Such an observation illustrates the value of such data in timing and monitoring activity during times when field observations are lacking: the presence or absence of activity can be confirmed. Although the Landsat satellite which carries TM has a repeat cycle of 16 days at the equator, due to the polewards convergence of polar orbits, images of Erebus $\left(77.58^{\circ} \mathrm{S}, 167.17^{\circ} \mathrm{E}\right)$ can be obtained during up to six different orbital tracks (paths 52 to 57). This means that Erebus is actually imaged $\sim$ six times every 16 days, greatly increasing the resolution of time series analysis and the chances of coinciding with a cloud-free period. All cloud-free TM scenes available from the US Geological Survey Land Information System (http://edcwww.cr.usgs.gov/webglis/) between 1984 and 1989 are given on figure 2(a). Twenty-four cloud-free scenes were available over this period (the TM was not operational prior to 1984) out of a total of 107, where the number of cloud-free images available ranged between three and six scenes per month (in December 1984 and January 1985 respectively). However, gaps in coverage occur during the summer months due to the sensor being turned off during these dark periods. A request to have the sensor turned on during these periods would rectify this, achieving year-round TM-coverage at a rate of 3-6 cloud-free scenes per month, as during the winter.

\subsection{TM-based lava lake thermal structure and area estimations}

A more quantitative approach has involved the development of methods to use TM thermal data to estimate the thermal structure of the lava lake surface, and in turn calculate the thermal and mass fluxes at the lake. Rothery et al. (1988) adapted the dual band approach initially applied to AVHRR data by Dozier (1981). This assumes that the lava lake fills the $900 \mathrm{~m}^{2} \mathrm{TM}$ band 5 or 7 pixels, and has a surface composed of two thermal components: a chilled crust in which cracks expose the higher temperature molten core, as observed by Flynn et al. (1993) at the Kupaianaha lava lake in Hawaii. Given emitted radiance in bands 5 and 7, the pixel integrated radiances (corrected for atmospheric, surface reflection and emissivity effects) in these two bands $\left(R_{5 \text { thermal }}\right.$ and $\left.R_{7 \text { thermal }}\right)$ can be described by

$$
\begin{aligned}
& R_{5 \text { thermal }}=p_{\mathrm{c}} L_{5}\left(T_{\mathrm{c}}\right)+\left(1-p_{\mathrm{c}}\right) L_{5}\left(T_{\mathrm{h}}\right) \\
& R_{7 \text { thermal }}=p_{\mathrm{c}} L_{7}\left(T_{\mathrm{c}}\right)+\left(1-p_{\mathrm{c}}\right) L_{7}\left(T_{\mathrm{h}}\right)
\end{aligned}
$$

In which $L_{x}(T)$ is the Planck function radiance from a blackbody of temperature $T$ at the wavelengths of band $x, T_{\mathrm{c}}$ and $T_{\mathrm{h}}$ are the temperatures of the crust and exposed molten core, and $p_{\mathrm{c}}$ is the pixel portion occupied by the crusted component. If any one of the three unknowns $\left(T_{\mathrm{c}}, T_{\mathrm{h}}\right.$ or $\left.p_{\mathrm{c}}\right)$ can be assumed, then the remaining two unknowns can be calculated by solution of these simultaneous equations.

Rothery et al. (1988) used unsaturated pixels at the periphery of the anomaly and assumed that the crusted component was too cool to contribute to $R_{5 \text { thermal }}$ or 
(a) Erebus lava lake area and cloud-free TM acquisitions

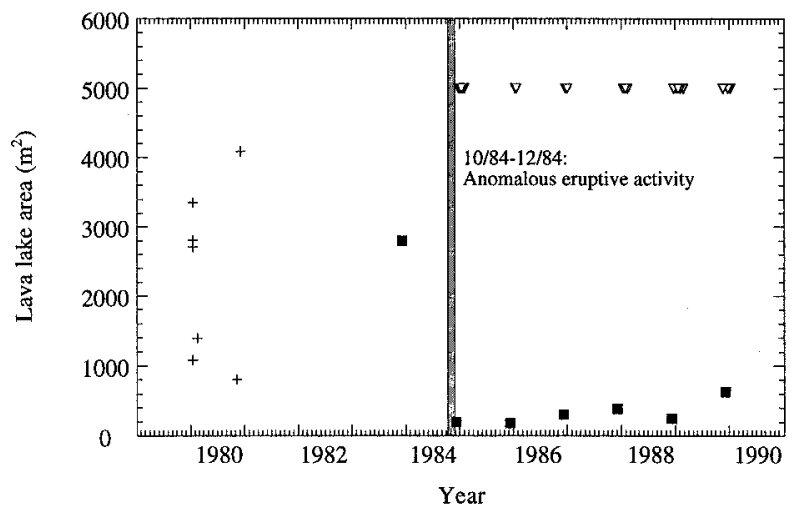

(b) Erebus $\mathrm{SO}_{2}$ flux

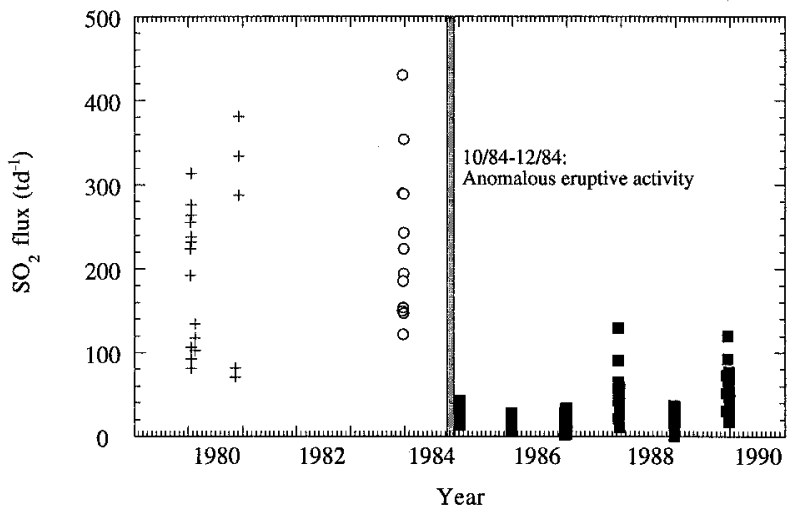

(c) Erebus mean monthly earthquakes per day

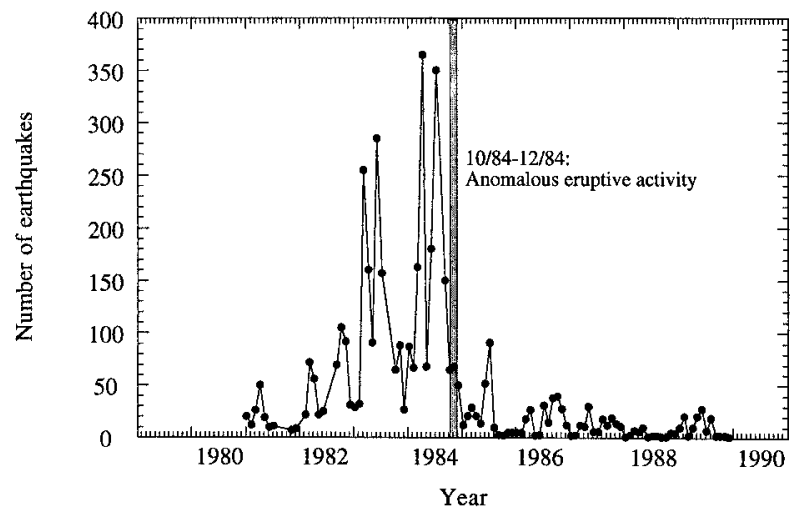

Figure 2. Erebus lava lake area $(a), \mathrm{SO}_{2}$ flux $(b)$, and monthly mean number of earthquakes per day $(c)$ between 1980 and 1989. Filled squares, open circles and crosses are taken from Kyle et al. (1994), Rose et al. (1985) and this study respectively, and seismic data in (c) are from Kaminuma (1994). Explosive activity of September to December 1984 is marked by a grey rectangle, and on $(a)$ all cloud-free TM scenes available from the US Geological Survey Land Information System are given by inverted triangles. 


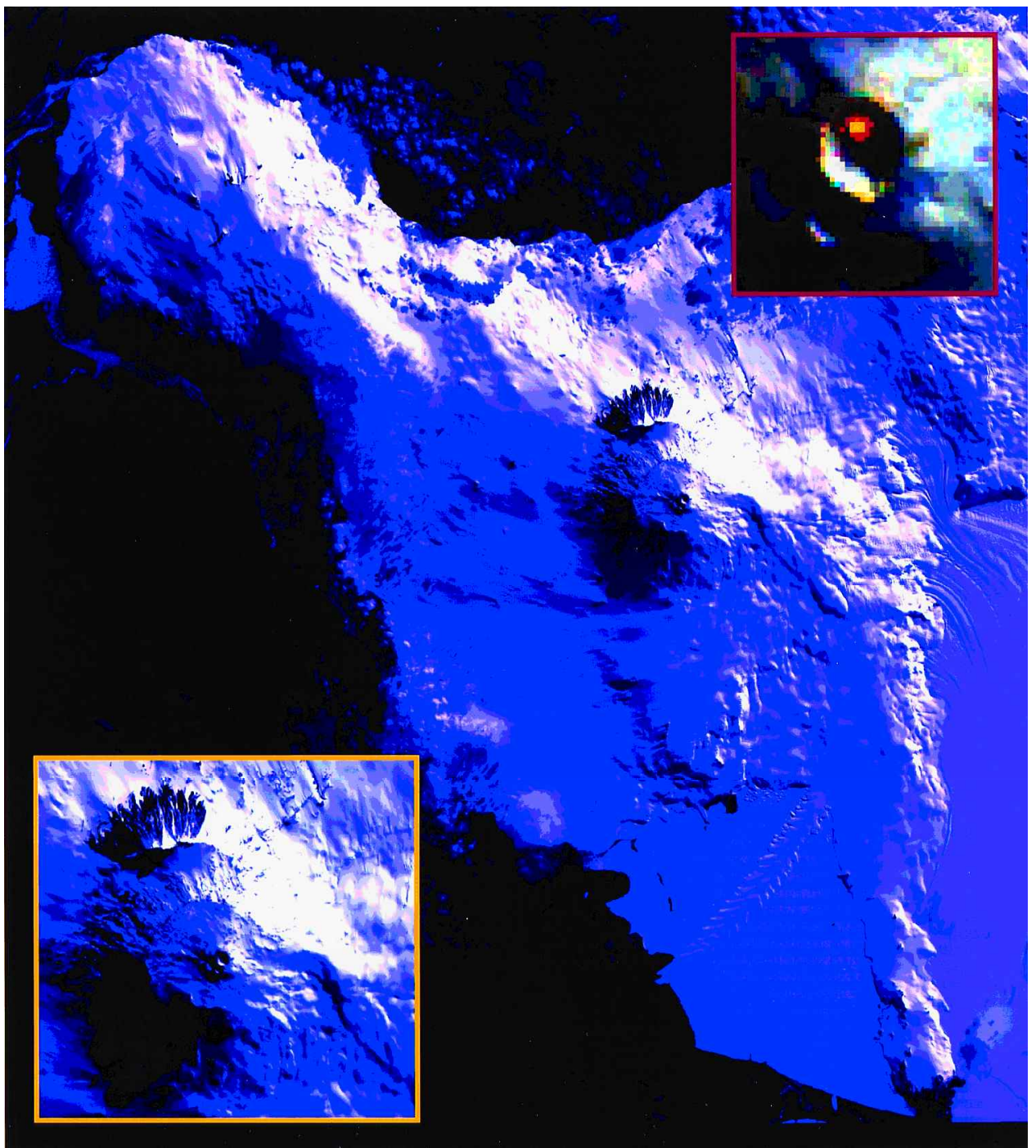

Figure 3 (and cover). Landsat-TM image of Ross Island and Erebus volcano (see figure 1) acquired on 29 January 1989. The main image and Erebus enlargement (inset bottom left) display bands 3,2 and 1, where snow and sea ice are apparent from the purple colours. On the Erebus enlargement (inset bottom left) the summit crater is apparent as a circular feature central to this enlargement. The summit and side craters are enlarged as inset top right. This enlargement gives the band 7, 5, 4 combination and reveals the hot-spot (yellow/red colours: radiant in bands 7 and 5) due to the lava lake in the north-east portion of the main crater.

$R_{7 \text { thermal }}$. This meant that equations (1a) and (1b) reduced to

$$
\begin{aligned}
& R_{5 \text { thermal }}=p_{\mathrm{h}} L_{5}\left(T_{\mathrm{h}}\right) \\
& R_{7 \text { thermal }}=p_{\mathrm{h}} L_{7}\left(T_{\mathrm{h}}\right)
\end{aligned}
$$

in which $p_{\mathrm{h}}$ is the pixel portion occupied by the molten component. These equations 
require no assumptions for solution, and gave $p_{\mathrm{h}}$ of $0.001-0.002$ and $T_{\mathrm{h}}$ of 900 $1130^{\circ} \mathrm{C}$ (Rothery et al. 1988). By counting and summing the area of radiant pixels, Glaze et al. (1989) estimated that the lake area $\left(A_{\text {lake }}\right)$ at this time was $35100 \mathrm{~m}^{2}$.

\subsection{A three band, three component approach}

However, Harris et al. (1999) have criticized these approaches for three main reasons. Firstly, it is unreasonable to assume that the crusted component does not contribute to $R_{5 \text { thermal }}$ or $R_{7 \text { thermal }}$. Given the typical values for $p_{\mathrm{c}}$ and $T_{\mathrm{c}}$ obtained by Flynn et al. (1993) at the Kupaianaha lava lake, the crusted component would contribute $8 \%$ and $37 \%$ of $R_{5 \text { thermal }}$ and $R_{7 \text { thermal }}$ respectively. This will result in an underestimation of $p_{\mathrm{h}}$ and an over-estimation of $T_{\mathrm{h}}$ (Harris et al. 1999). Secondly, because the area of the molten component will be small, the crusted component will dominate heat loss. As a result, use of just the molten component to estimate heat flux will result in considerable underestimates of the true heat flux (see also Oppenheimer and Francis 1997). Finally, the lava lake will be a sub-pixel feature, attaining an area of just $\sim 180 \mathrm{~m}^{2}$ (from Kyle 1986) at the time of the January 1985 image compared with a pixel area of $900 \mathrm{~m}^{2}$. Thus pixel-count-based area estimates grossly overestimate the true lava lake area (compare the TM-based estimate of $35100 \mathrm{~m}^{2}$ with the ground-based estimate of $180 \mathrm{~m}^{2}$ ). Equations (1a) and (1b) will also have to include a third thermal component to take into account ground at ambient temperatures surrounding the sub-pixel lava lake.

Harris et al. (1999) therefore preferred to take a three-component approach using the radiant $14400 \mathrm{~m}^{2}$ band 6 lava lake pixel $\left(R_{6 \text { thermal }}\right)$ and the integrated radiance of the 16 band 5 and 7 pixels falling within the larger band 6 pixel $\left(R_{5 \text { int }}\right.$ and $R_{7 \text { int }}$, appendix A). Where:

$$
\begin{gathered}
R_{6 \text { thermal }}=p_{\mathrm{b}} L_{6}\left(T_{\mathrm{b}}\right)+p_{\mathrm{h}} L_{6}\left(T_{\mathrm{h}}\right)+\left(1-p_{\mathrm{b}}-p_{\mathrm{h}}\right) L_{6}\left(T_{\mathrm{c}}\right) \\
R_{7 \text { int }}=p_{\mathrm{b}} L_{7}\left(T_{\mathrm{b}}\right)+p_{\mathrm{h}} L_{7}\left(T_{\mathrm{h}}\right)+\left(1-p_{\mathrm{b}}-p_{\mathrm{h}}\right) L_{7}\left(T_{\mathrm{c}}\right) \\
R_{5 \text { int }}=p_{\mathrm{b}} L_{5}\left(T_{\mathrm{b}}\right)+p_{\mathrm{h}} L_{5}\left(T_{\mathrm{h}}\right)+\left(1-p_{\mathrm{b}}-p_{\mathrm{h}}\right) L_{5}\left(T_{\mathrm{c}}\right)
\end{gathered}
$$

in which $p_{\mathrm{b}}$ is the pixel portion occupied by ambient ground surrounding the subpixel lava lake, and $T_{\mathrm{b}}$ is the temperature of that ground. Rearranging equation (3a) so that

$$
\beta_{6}=\left\{R_{6 \text { thermal }}-L_{6}\left(T_{\mathrm{c}}\right)-p_{\mathrm{h}}\left[L_{6}\left(T_{\mathrm{h}}\right)-L_{6}\left(T_{\mathrm{c}}\right)\right]\right\} /\left[L_{6}\left(T_{\mathrm{b}}\right)-L_{6}\left(T_{\mathrm{c}}\right)\right]
$$

and substituting $p_{\mathrm{b}}$ in equations $(3 \mathrm{~b})$ and $(3 \mathrm{c})$ with $\beta_{6}$ reduces the number of unknowns to four $\left(T_{\mathrm{b}}, T_{\mathrm{h}}, T_{\mathrm{c}}\right.$ and $\left.p_{\mathrm{h}}\right) . T_{\mathrm{b}}$ can be estimated using typical temperatures from background pixels surrounding the lakes and $T_{\mathrm{h}}$ has been measured at $(1000 \pm 40)^{\circ} \mathrm{C}($ Kyle 1977, McClelland et al. 1989). Assuming these values and using equations (3b), (3c) and (4) therefore allows $T_{\mathrm{c}}$ and $p_{\mathrm{h}}$ to be calculated if unsaturated data are available (appendix A). Solution would enable the lava lake area to be estimated by multiplying the sum of $p_{\mathrm{c}}\left(=1-p_{\mathrm{b}}-p_{\mathrm{h}}\right)$ and $p_{\mathrm{h}}$ by pixel area $\left(14400 \mathrm{~m}^{2}\right)$.

However saturation of bands 5 and 7 meant that the equation (3a) to (4) approach could not be applied. Instead, the approach was adapted by rearranging equation (3a) to calculate $p_{\mathrm{h}}$ from:

$$
p_{\mathrm{h}}=\left\{R_{6 \text { thermal }}-L_{6}\left(T_{\mathrm{c}}\right)-p_{\mathrm{b}}\left[L_{6}\left(T_{\mathrm{b}}\right)-L_{6}\left(T_{\mathrm{c}}\right)\right]\right\} /\left[L_{6}\left(T_{\mathrm{h}}\right)-L_{6}\left(T_{\mathrm{c}}\right)\right]
$$

Assuming $T_{\mathrm{b}}$ and $T_{\mathrm{h}}$ as before leaves two unknowns in the right-hand term $\left(p_{\mathrm{b}}\right.$ and 
$T_{\mathrm{c}}$ ). The area of the Erebus lava lake is well known, being estimated from the ground every austral summer. Because TV camera data show no significant fluctuations over 6-month-long periods, the lake area can be assumed to be approximately constant over such time periods (Kyle et al. 1994). Parameter $p_{\mathrm{b}}$ can therefore be estimated from $p_{\mathrm{b}}=A_{\text {lake }} / A_{\text {pixel }}$, in which $A_{\text {pixel }}$ is $14400 \mathrm{~m}^{2}$ : the area of the band 6 pixel. Lake areas of 180 and $300 \mathrm{~m}^{2}$ in 1985 and 1989 respectively can be set using lake dimensions given in Kyle (1986) and McClelland et al. (1989), giving $p_{\mathrm{b}}$ of 0.0125 and 0.0208 on the two dates respectively. However $T_{\mathrm{c}}$, being highly variable, is more difficult to assume. Flynn et al. (1993) found that $T_{\mathrm{c}}$ could vary between 80 and $790^{\circ} \mathrm{C}$ at the Kupaianaha lava lake. Therefore Harris et al. (1999) solved equation (5) using a range of $p_{\mathrm{h}}$ and $T_{\mathrm{c}}$. Because the integrated band 5 radiance was saturated, the lower limit to $p_{\mathrm{h}}$ (upper limit on $p_{\mathrm{c}}$ ) was set using the combination of $p_{\mathrm{h}}$ and $T_{\mathrm{c}}$ that would just saturate band 5 . Conversely, because the integrated band 4 radiance showed no response to the high temperature source, the upper limit to $p_{\mathrm{h}}$ (lower limit on $p_{\mathrm{c}}$ ) was set using the combination of $p_{\mathrm{h}}$ and $T_{\mathrm{c}}$ that would not quite achieve measurable emitted radiance in band 4 . The limits placed by this approach on possible ranges of lake surface thermal parameters are given in table 1 .

Solution for the 1985 image required a higher $T_{\mathrm{c}}$ than in $1989\left(788^{\circ} \mathrm{C}\right.$ as opposed to $\left.397^{\circ} \mathrm{C}\right)$ or a much higher $p_{\mathrm{h}}(0.0091$ as opposed to 0.0075$)$. These higher values suggest that the lake surface was much hotter in 1985, with an effective radiation temperature $\left(T_{\mathrm{e}}\right.$, appendix B) of $788-903^{\circ} \mathrm{C}$ as opposed to $578-715^{\circ} \mathrm{C}$ in 1989. Harris et al. (1999) suggest two reasons for these differences. First, the 1985 image

Table 1. Thermal parameters and magma mass flux estimates derived from TM data, except for $A_{\text {lake }}$ and $T_{\mathrm{h}}$ which are taken from the given references, and $Q_{\text {gas }}$ and $M$ which are calculated using parameters obtained using TM along with other data sources as indicated.

\begin{tabular}{lll}
\hline Image date & 26 January 1985 & 29 January 1989 \\
\hline$A_{\text {lake }}\left(\mathrm{m}^{2}\right)$ & $180(\mathrm{~A})$ & $300(\mathrm{~B})$ \\
$\mathrm{A}_{\mathrm{pixel}}$ & 14400 & 14400 \\
$\left.T_{\mathrm{h}}{ }^{\circ} \mathrm{C}\right)$ & $1000(\mathrm{C})$ & $1000(\mathrm{C})$ \\
$T_{\mathrm{c}}\left({ }^{\circ} \mathrm{C}\right)$ & $100-788$ & $100-397$ \\
$p_{\mathrm{h}}$ & $0-0.0091$ & $0.0027-0.0075$ \\
$f_{\mathrm{h}}$ & $0-0.73$ & $0.13-0.36$ \\
$p_{\mathrm{c}}$ & $0.0034-0.0125$ & $0.0133-0.0181$ \\
$f_{\mathrm{c}}\left({ }^{\circ} \mathrm{C}\right)$ & $0.27-1.0$ & $0.64-0.87$ \\
$T_{\mathrm{e}}$ & $788-903$ & $578-715$ \\
$Q_{\text {rad }}(\mathrm{MW})$ & $12-18$ & $8-15$ \\
$Q_{\text {conv }}(\mathrm{MW})$ & 2 & 3 \\
$Q_{\text {gas }}(\mathrm{MW})$ & $2-83(\mathrm{D})$ & $2-90(\mathrm{D})$ \\
$Q_{\mathrm{tot}}(\mathrm{MW})$ & $16-103(\mathrm{E})$ & $13-108(\mathrm{E})$ \\
$M\left(\mathrm{~kg} \mathrm{~s}{ }^{-1}\right)$ & $38-76(\mathrm{~F})$ & $30-69(\mathrm{~F})$ \\
\hline
\end{tabular}

A From Kyle (1986).

B From McClelland et al. (1989).

C From Kyle (1977) and McClelland et al. (1989).

D Calculated (appendix C) using $\mathrm{SO}_{2}$ flux data from Kyle et al. (1994) and gas ratios taken from Anderson (1975) and Gerlach (1982).

E $Q_{\text {tot }}=Q_{\text {rad }}+Q_{\text {conv }}+Q_{\text {gas }}$.

F Calculated (appendix C) using TM derived parameters with magma temperature crystallization data taken from Kyle (1977) and Dunbar et al. (1994) and magma cooling equal to the typical liquidus-solidus difference given by Archambault and Tanguy (1976). 
may have coincided with an overturning period or gas bubble burst. During such events the crust will founder or be disrupted, exposing greater areas of the molten core. Shortly after such periods the newly formed crust will be thin and closer to magmatic temperatures, as it begins to cool from the magmatic $\left(\sim 1000^{\circ} \mathrm{C}\right)$ temperature (Flynn et al. 1993). This would explain the high $T_{\mathrm{c}}$ or $p_{\mathrm{h}}$. However, such periods are anomalous. Flynn et al. (1993) found that $90 \%$ of the time the Kupaianaha lava lake was characterized by quiescence during which time the crust was extensive (covering $>99.99 \%$ of the surface), thick and cool $\left(100-340^{\circ} \mathrm{C}\right)$. An alternative explanation was found through the use of cubic convolution data from the 1985 image. Such resampling is undesirable for quantitative analysis, as it can modify pixel digital numbers (DN) by up to 40 (estimated from comparisons of cubic convolution resampled data with raw data given in Flynn (1992)). Using Oppenheimer et al. (figure 5, 1993), such variations in DN can result in errors in estimated $T_{\mathrm{c}}$ of up to $\sim 100^{\circ} \mathrm{C}$ and an order of magnitude difference in derived $p_{\mathrm{h}}$.

\subsection{Thermal and mass fluxes}

The estimated thermal structure of the lake surface can be used to estimate the heat loss from that surface, and in turn the mass flux of magma necessary to maintain that heat flux (appendix C). Table 1 shows that a supply of $30-76 \mathrm{~kg} \mathrm{~s}^{-1}$ is required to maintain measured heat losses at the lake. However very little of this supply is erupted from the lake. Therefore, to maintain stable lake volume and level at Erebus, Harris et al (1999) postulated the following model. Gas-rich, hot, buoyant magma ascends the conduit linking the lake to a deep magma reservoir. At the lake the magma degasses, cools and increases in density to sink back down the conduit at roughly the same rate as magma ascends it (i.e. $30-76 \mathrm{~kg} \mathrm{~s}^{-1}$ ). The sinking mass may then either be intruded within or beneath the edifice, and/or be mixed with the reservoir magma. Because the deformation data of Otway et al. (1994) show no evidence of the deformation that would result if mass was emplaced within the edifice, this mass-loss mechanism can be discounted. However, the chamber cooling of $10-15^{\circ} \mathrm{C}$ found by Caldwell and Kyle (1994) and multiple growth phases of phenocrysts identified by Dunbar et al. (1994) suggest that the sinking mass may mix with the reservoir magma (to cool and evolve the reservoir magma) and be recycled. Such mechanisms are characteristic of many of this planet's persistently active volcanoes (Andres et al. 1991, Francis et al. 1993, Allard et al. 1994, Kazahaya et al. 1994, Allard 1997, Harris and Stevenson 1997, Harris et al. 1999). Understanding these processes at Erebus may therefore contribute to understanding the operation of persistently active volcanoes world-wide.

\subsection{Low spatial resolution data: the Advanced Very High Resolution Radiometer}

Although AVHRR has an inferior spatial resolution when compared with TM, $1.1 \mathrm{~km}$ at nadir as opposed to $30-120 \mathrm{~m}$, the AVHRR has a far greater temporal resolution. At the equator each NOAA satellite on which the AVHRR is carried has a return period of 12 hours. By ensuring that two satellites are always in orbit, a 6-hour return period is maintained. Due to the orbit convergence at the Erebus latitudes (figure 1), 5 images per day can be acquired using a single satellite, or $\sim 10$ using two satellites. AVHRR data are collected at the McMurdo station on Ross Island (figure 1) and are archived at the Arctic and Antarctic Research Center (http://arcane.ucsd.edu/). This dataset therefore offers great potential for detailed time series monitoring of the lake. 
However, because the lava lake is situated on the floor of a $\sim 240 \mathrm{~m}$ deep crater and the AVHRR views targets from a look angle of $\pm 55^{\circ}$, some images will be unusable due to topographic shielding of the lake (figure 4). Using the crater and

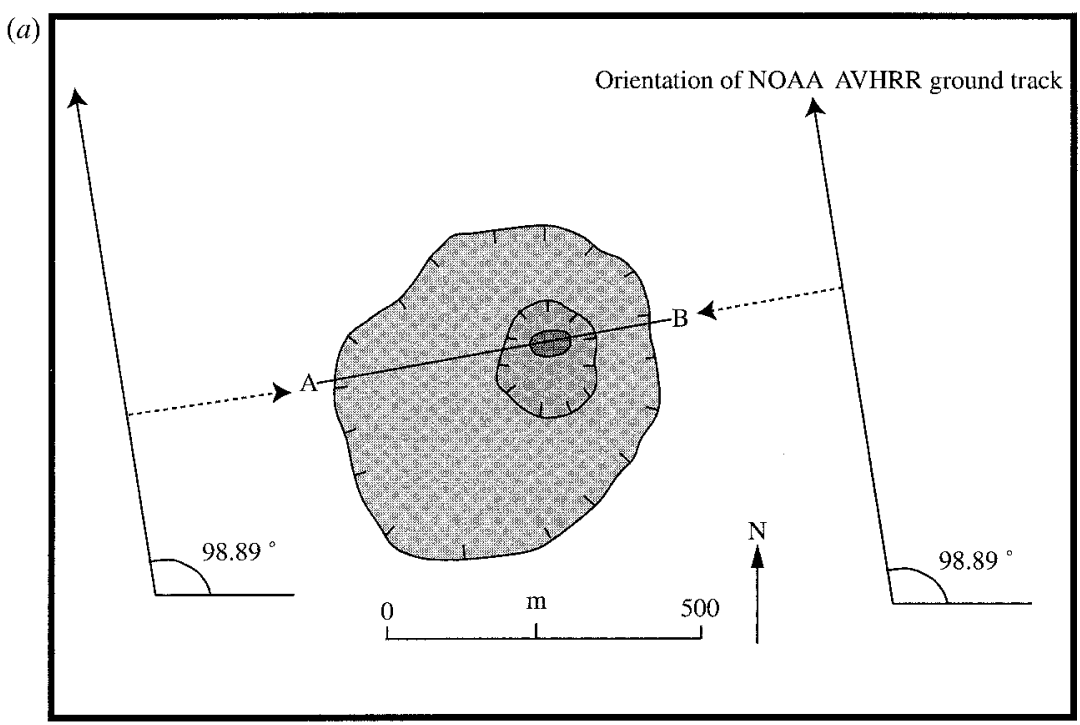

(b)

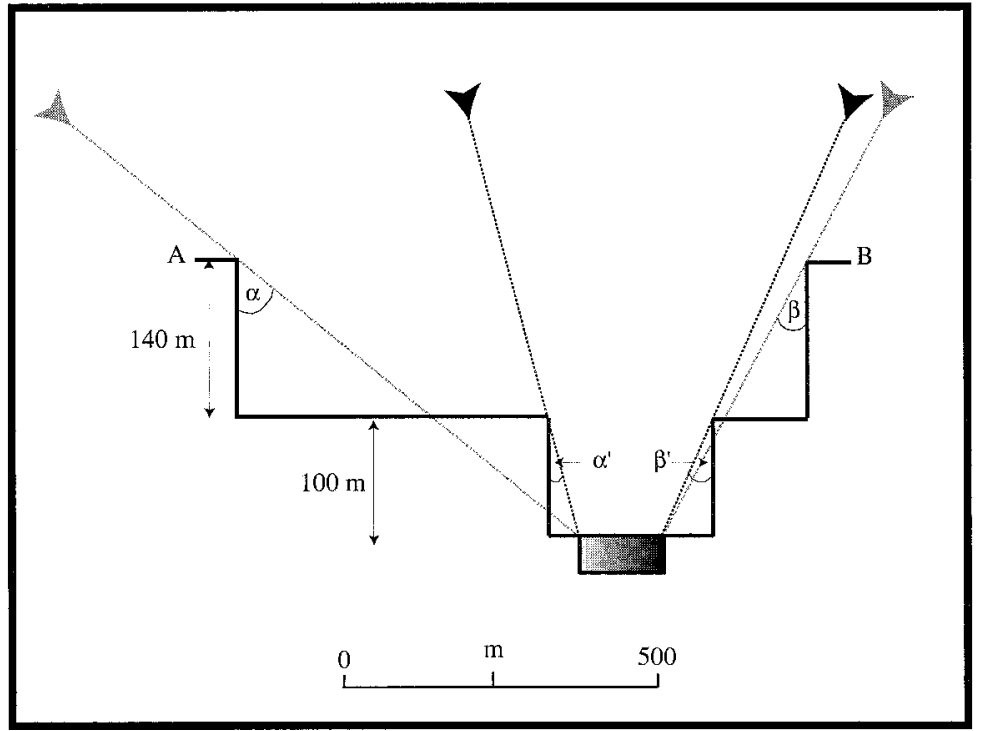

Figure 4. AVHRR viewing geometry for a pass to the east and west of the Erebus summit craters (NB AVHRR orbits are inclined at an angle of $98.89^{\circ}$ ). Dashed arrows and solid line A-B on $(a)$ indicate the trend of the AVHRR scan line. (b) The crater in profile across the AVHRR scan-line transect A-B. Crater and lava lake dimensions are taken from McClelland et al. (1989), Dibble et al. (1994a) and Otway et al. (1994). In the absence of the inner crater the geometry defined by the grey line of sight and angles $\alpha$ (for a westerly pass) and $\beta$ (for an easterly pass) would apply. However, the presence of the $100 \mathrm{~m}$ deep inner crater means that the geometry defined by the black line of sight and angles $\alpha^{\prime}$ (for a westerly pass) and $\beta$ (for an easterly pass) apply. 
lava lake dimensions and geometries shown in figure 4 (see also Harris et al. 1997) the lake will begin to become obscured at a scan angle of $33 \pm 6^{\circ}$ or $24 \pm 13^{\circ}$, when viewed from a pass to the east and west of the crater, respectively, and will become completely obscured at $39 \pm 9^{\circ}$ and $32 \pm 14^{\circ}$ (figure 4 ). This means that only images within $33 \pm 6^{\circ}$ or $24 \pm 13^{\circ}$ of nadir, depending on the location of the pass, should be used for quantitative analysis (as only on these images is an unobscured view of the lake guaranteed), but the lake should be detectable out to $39 \pm 9^{\circ}$ or $32 \pm 14^{\circ}$.

Figure 5 shows the detection capability of the AVHRR over hot, active lava targets, such as the Erebus lava lake. Although over ambient ground the channel 3 and 4 brightness temperatures $\left(T_{3}\right.$ and $\left.T_{4}\right)$ are similar, where differences of $\sim 5^{\circ} \mathrm{C}$ are due to differential atmospheric, emissivity and reflection effects, over the lava lake the $T_{3}-T_{4}$ difference rises to $>10^{\circ} \mathrm{C}$, creating an easily detectable thermal anomaly. This is due to the superior sensitivity of channel 3 to sub-pixel hot-spots. This causes a major anomaly in channel $3(3.55-3.93 \mu \mathrm{m})$, whereas the inferior sensitivity of channel $4(10.5-11.5 \mu \mathrm{m})$ causes the anomaly in this channel to be far more subdued (Harris et al. 1997). Although for a high temperature feature of this size (10-60 m across) only a single pixel anomaly should result, pixel overlap and the point spread function of the sensor causes anomalous radiance to be spread from the lava lake pixel into adjacent pixels, causing a $2-3$ pixel anomaly especially in channel 3. The anomalously low $T_{3}$ and negative $T_{3}-T_{4}$ at the downscan edge of the anomaly is a common feature in AVHRR data over high temperature features, and is an anomalous downscan response of the sensor to such high temperature targets. Harris (1996), Higgins and Harris (1997) and Harris et al. (1997) give a full discussion of these issues.

Although Wiesnet and D'Aguanno (1982) showed that the lava lake at Erebus was easily detectable as a thermal anomaly in AVHRR channel 3 using an image acquired on 10 February 1980 (as also shown in figure 5), few attempts have been made to use the data any further. This is in spite of the fact that, with 5-10 AVHRR images per day received at the McMurdo station, this dataset could be extremely valuable if only for a qualitative assessment of whether or not the lava lake is active.

\subsection{AVHRR-based lava lake area estimations}

Here we demonstrate a method that also allows the lake area, $\mathrm{SO}_{2}$, thermal and mass fluxes to be estimated with reasonable accuracy. We examined seven AVHRR images of Erebus obtained from passes to the west of the crater on which Erebus was within $25^{\circ}$ of nadir. Two of these can be viewed in Rothery and Oppenheimer (1994, figure 1), and the transects across the lava lake in channels 3 and 4 are given in figure 5. Because channel 3 is saturated for most images, we use the unsaturated data provided by channel 4 , and calculate the lava lake area from:

$$
p_{\text {lake }}=\left[R_{4 \text { thermal }}-L_{4}\left(T_{\mathrm{b}}\right)\right] /\left[L_{4}\left(T_{\mathrm{e}}\right)-L_{4}\left(T_{\mathrm{b}}\right)\right]
$$

In which $p_{\text {lake }}$ is the pixel portion occupied by the lake, $R_{4 \text { thermal }}$ is the channel 4 pixel-integrated radiance (corrected for atmospheric effects, emissivity and nonlinearity), $T_{\mathrm{e}}$ is the effective radiation temperature of the lake surface, and $T_{\mathrm{b}}$ is the temperature of the ground surrounding the lava lake. We solve this equation by setting $T_{\mathrm{b}}$ to the mean temperature obtained from channel 4 pixels immediately adjacent to the anomaly. We then set the remaining unknown, $T_{\mathrm{e}}$, to the typical $T_{\mathrm{e}}$ obtained from the TM data (table 1), where, for reasons described in $\$ 2.3$ we find $578-715^{\circ} \mathrm{C}$ the most trustworthy range for $T_{\mathrm{e}}$. We then solve equation (6) while 

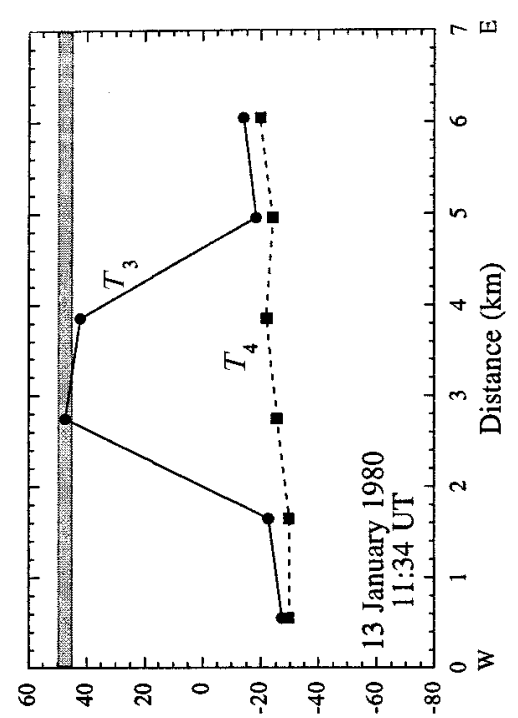

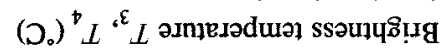

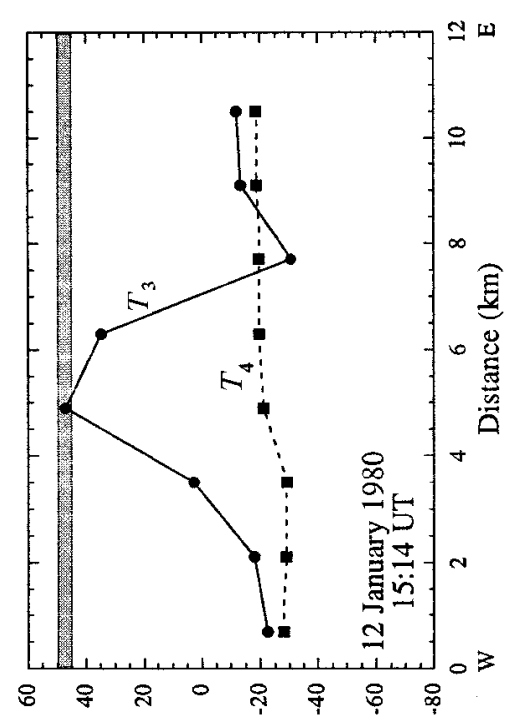

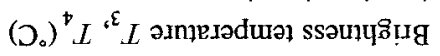

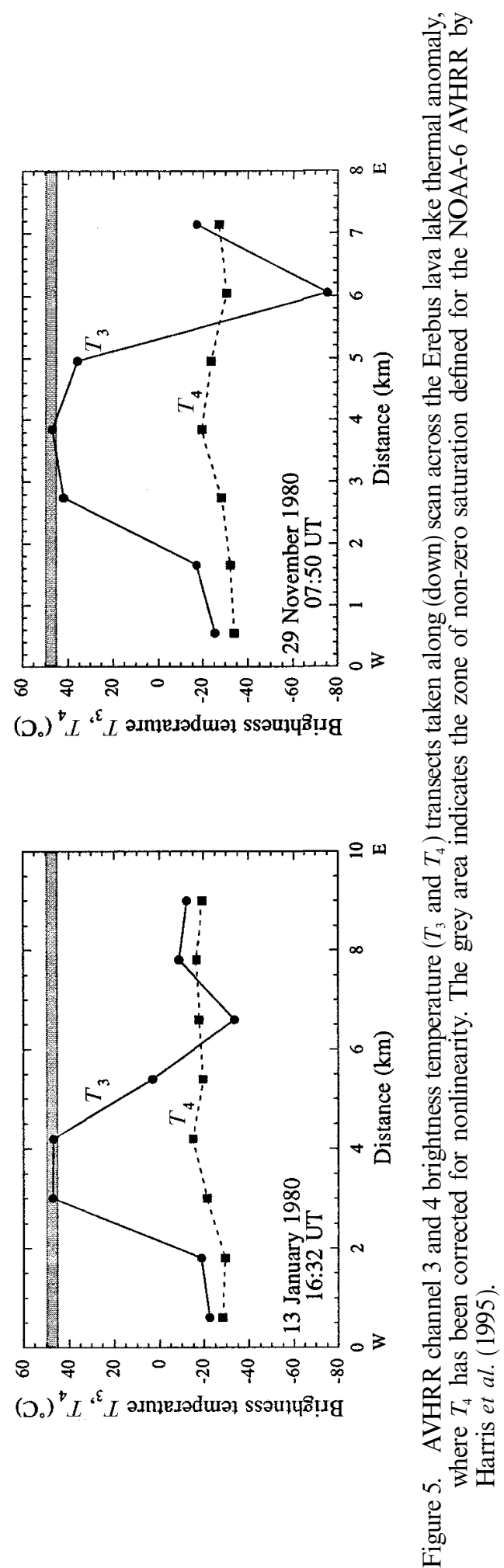


ensuring that the derived thermal structure is sufficient to account for saturation of channel 3. By calculating pixel area $\left(A_{\text {pixel }}\right)$ as a function of scan angle using the procedure and field of view inputs given by Harris et al. (1997), we obtain lake area from:

$$
A_{\text {lake }}=p_{\text {lake }} A_{\text {pixel }}
$$

Using this approach we obtain $A_{\text {lake }}$ typically in the range $1000-4000 \mathrm{~m}^{2}$ (table 2). This range is consistent with ground-based estimates for the lake area around 1980. From sketch maps of the lake in January 1978 (McClelland et al. 1989, figure 18-2), we obtain lake dimensions of $60 \mathrm{~m} \times 40 \mathrm{~m}$ and an area of $\sim 2400 \mathrm{~m}^{2}$. In December 1980 the lake was estimated at $4500 \mathrm{~m}^{2}$ (dimensions of $100 \mathrm{~m} \times 60 \mathrm{~m}$; McClelland et al. 1989). However, airphoto mapping gave dimensions of $60 \mathrm{~m} \times 45 \mathrm{~m}$ and an area of $2800 \mathrm{~m}^{2}$ for the roughly oval lake (McClelland et al. 1989, Kyle et al. 1994). This latter lake area is in excellent agreement with the area that we obtained (table 2). Variation in our estimates may be due to variable amounts of plume contaminating the signal or sub-pixel cloud, topographic shielding, and/or variations in the lake area and activity. We note that yearly variations in the lake level and dimensions are commonly reported (McClelland et al. 1989).

Harris et al. (1997) used the same AVHRR data to estimate a lava lake area of $6000-32000 \mathrm{~m}^{2}$. This, like the TM-based estimate of Glaze et al. (1989), is clearly in excess of ground-based estimates. The approach of Harris et al. (1997) used a twocomponent pixel model as in equation (6), but differed from our approach in that it assumed that the contribution of the molten component to the channel 4 radiance $\left(R_{\text {thermat al }}\right)$ was negligible and could therefore be ignored. Equation (6) could then be solved if the crust temperature $\left(T_{\mathrm{c}}\right)$ could be assumed, where Harris et al. (1997) took a range of $100-500^{\circ} \mathrm{C}$ for $T_{\mathrm{c}}$. Using the thermal surface structure obtained by us for the Erebus lake using TM data (table 1), we find that this assumption is unsound because the molten component can be as significant in its contribution to $R_{4 \text { thermal }}$ as the crustal component (where they can both contribute around $1 \%$ of $\left.R_{4 \text { thermal }}\right)$. We therefore avoid this assumption by using the effective radiation temperature $\left(T_{\mathrm{e}}\right)$, and find that the Harris et al. (1997) overestimate is a result of (1) ignoring the molten component and thus (2) the $100-500^{\circ} \mathrm{C}$ range used being too low to describe the true lake surface temperature (i.e. $T_{\mathrm{e}}$, table 1). Reference to equation (6) shows that reducing $T_{\mathrm{e}}$ will increase the calculated $p_{\text {lake }}$ and hence $A_{\text {lake }}$.

Table 2. AVHRR image details and derived lava lake areas using the effective lava lake surface temperature $\left(T_{\mathrm{e}}\right)$ obtained using TM.

\begin{tabular}{|c|c|c|c|c|c|c|}
\hline \multirow[b]{2}{*}{ Date } & \multirow[b]{2}{*}{$\begin{array}{l}\text { Time } \\
\text { (UT) }\end{array}$} & \multirow[b]{2}{*}{$\begin{array}{c}\text { Scan angle } \\
\text { (degrees) }\end{array}$} & \multicolumn{2}{|c|}{$T_{\mathrm{e}}=578\left({ }^{\circ} \mathrm{C}\right)$} & \multicolumn{2}{|c|}{$T_{\mathrm{e}}=715\left({ }^{\circ} \mathrm{C}\right)$} \\
\hline & & & $p_{\text {lake }}$ & $\begin{array}{l}A_{\text {lake }} \\
\left(\mathrm{m}^{2}\right)\end{array}$ & $p_{\text {lake }}$ & $\begin{array}{l}A_{\text {lake }} \\
\left(\mathrm{m}^{2}\right)\end{array}$ \\
\hline $12 / 1 / 80$ & 15: 14 & 24.0 & 0.001998 & 3096 & 0.001502 & 2327 \\
\hline $13 / 1 / 80$ & 09: 53 & 25.0 & 0.002012 & 3209 & 0.001512 & 2412 \\
\hline $13 / 1 / 80$ & $11: 34$ & 5.5 & 0.001087 & 1236 & 0.000817 & 929 \\
\hline $13 / 1 / 80$ & $16: 32$ & 13.0 & 0.003367 & 3829 & 0.002530 & 2877 \\
\hline $10 / 2 / 80$ & 18: 08 & 12.6 & 0.001304 & 1590 & 0.000980 & 1195 \\
\hline $7 / 11 / 80$ & $15: 30$ & 23.8 & 0.000605 & 932 & 0.000442 & 681 \\
\hline $29 / 11 / 80$ & $07: 50$ & 9.1 & 0.003988 & 4666 & 0.00300 & 3509 \\
\hline
\end{tabular}




\subsection{AVHRR-based sulphur dioxide flux estimations}

Kyle et al. (1994) found a relationship between lava lake area and $\mathrm{SO}_{2}$ emissions, where emissions were proportional to the lake area (figure 6). Kyle et al. (1994) concluded that 'an important consequence of the observed relationship between $\mathrm{SO}_{2}$ emissions and lava lake area is that it allows us to predict emission rates when (ground-based) correlation spectrometer (COSPEC) measurements were not available.' This means that AVHRR potentially allows $\mathrm{SO}_{2}$ flux to be estimated during periods when it is impossible to visit the summit (e.g. during the austral winter). For 1980, using the linear equation given in figure 6 with our AVHRR-estimated lake areas, gives $\mathrm{SO}_{2}$ flux of $60-380 \mathrm{td}^{-1}$ (table 3 ). This was prior to the first measurement of $\mathrm{SO}_{2}$ at Erebus, but is in agreement with the nearest COSPEC measurement made by Rose et al. (1985) in December 1983 of $(230 \pm 90) \mathrm{td}^{-1}$. Because Kyle et al. (1994) imply that activity at the lake was stable over the 1980-1983 period, we assume that these two fluxes should be comparable.

\subsection{AVHRR-based thermal and mass fluxes}

Using the AVHRR-derived lake area with gas fluxes calculated using the estimated $\mathrm{SO}_{2}$ flux and TM-based $T_{\mathrm{e}}$, we estimate mass and thermal fluxes (table 3 ). The AVHRR-derived mass fluxes for $1980\left(100-640 \mathrm{~kg} \mathrm{~s}^{-1}\right.$, table 3) are an order of magnitude higher than those obtained between 1985 and 1989 using TM $\left(30-76 \mathrm{~kg} \mathrm{~s}^{-1}\right.$, table 1$)$.

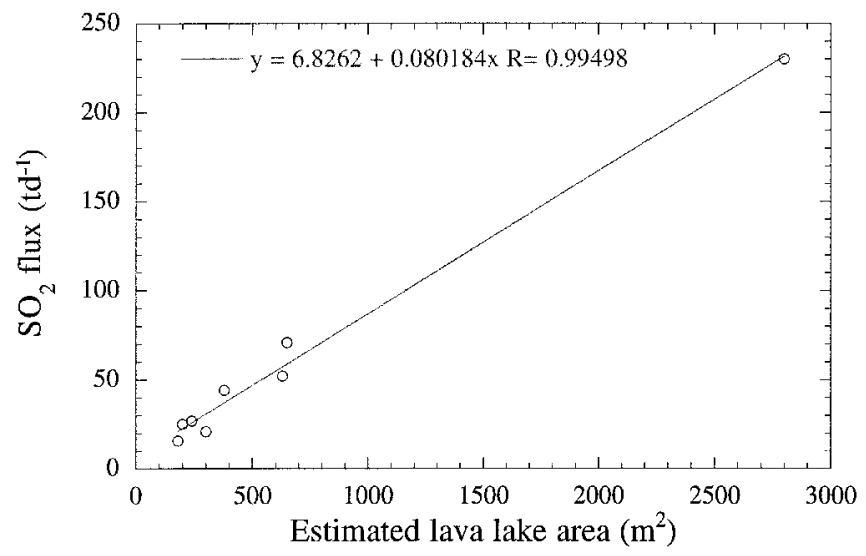

Figure 6. The relationship between $\mathrm{SO}_{2}$ flux and estimated lava lake area given by Kyle et al. (1994).

Table 3. Gas, thermal and mass fluxes derived from AVHRR data.

\begin{tabular}{lcccccc}
\hline Date & Time (UT) & $\begin{array}{c}\mathrm{SO}_{2} \text { flux } \\
\left(\mathrm{td}^{-1}\right)\end{array}$ & $\begin{array}{c}Q_{\text {gas }} \\
(\mathrm{MW})\end{array}$ & $\begin{array}{c}Q_{\mathrm{rad}} \\
(\mathrm{MW})\end{array}$ & $\begin{array}{c}Q_{\text {conv }} \\
(\mathrm{MW})\end{array}$ & $\begin{array}{c}M \\
\left(\mathrm{~kg} \mathrm{~s}^{-1}\right)\end{array}$ \\
\hline $12 / 1 / 80$ & $15: 14$ & $193-255$ & $16-855$ & $113-83$ & $32-37$ & $350-423$ \\
$13 / 1 / 80$ & $09: 53$ & $200-264$ & $17-885$ & $117-86$ & $33-39$ & $365-438$ \\
$13 / 1 / 80$ & $11: 34$ & $81-106$ & $7-355$ & $45-33$ & $13-15$ & $140-169$ \\
$13 / 1 / 80$ & $16: 32$ & $238-314$ & $20-1053$ & $140-103$ & $39-46$ & $415-523$ \\
$10 / 2 / 80$ & $18: 08$ & $103-134$ & $9-449$ & $58-43$ & $16-19$ & $181-216$ \\
$7 / 11 / 80$ & $15: 30$ & $61-82$ & $5-275$ & $33-25$ & $9-11$ & $105-123$ \\
$29 / 11 / 80$ & $07: 50$ & $288-381$ & $24-1277$ & $171-125$ & $48-56$ & $528-639$ \\
\hline
\end{tabular}


This reduction in mass flux between 1980 and 1985 is consistent with a change in activity at the lava lake over this period. Prior to September 1984, lava lake area was stable at $\sim 2300 \mathrm{~m}^{2}$ (mean from table 2), with $\mathrm{SO}_{2}$ fluxes of $\sim 200 \mathrm{td}^{-1}$ (mean table 3). These AVHRR-derived values are similar to the $A_{\text {lake }}$ of $2800 \mathrm{~m}^{2}$ given in Kyle et al. (1994) and $\mathrm{SO}_{2}$ flux of $230 \pm 90 \mathrm{td}^{-1}$ given by Rose et al. (1985) around this time (figure 2). However, during September 1984 strombolian eruptions increased in size and frequency, burying the lava lake (Caldwell and Kyle 1994). By January 1985, activity had returned to pre-September 1984 levels and the lava lake began to be exhumed (Caldwell and Kyle 1994, see also \$2.1). Following this event, however, ground-based lake area and $\mathrm{SO}_{2}$ fluxes were recorded at much lower levels of 200$650 \mathrm{~m}^{2}$ and $16 \pm 7$ to $71 \pm 20 \mathrm{td}^{-1}$ respectively (Kyle et al. 1994, figure 2). Caldwell and Kyle suggest that the 1984 event was due to injection of a new volatile-rich magma batch into the magma reservoir, degassing of which contributed to the increase in gas-powered explosive activity. Whatever the cause, it appears that following the event lake area and $\mathrm{SO}_{2}$ flux decreased by an order of magnitude, which was matched by an order of magnitude decrease in mass flux (figure 2). The event apparently marked a decrease in the supply to the lava lake; where possibly the explosive activity modified the conduit system and/or the injection of a new magma batch affected convection in the deeper reservoir.

\subsection{Synergistic use of TM and AVHRR at Erebus}

Using TM, if a ground-based measurement of the lava lake can be obtained, the thermal structure of the Erebus lake can be estimated which in turn allows radiative and convective heat losses to be estimated (appendix C). However, to estimate heat carried by the gas phase, and hence total heat flux (appendix C), ground-based measurements of $\mathrm{SO}_{2}$ flux (e.g. Kyle et al. 1994) along with gas ratio data (e.g. Anderson 1975, Gerlach 1982) are required (Harris et al. 1999). If $T_{\mathrm{e}}$ can be estimated using TM data on a yearly basis and used for AVHRR-derived lake area estimates, the apparent reliability of our AVHRR-derived lake area estimates given here means that AVHRR can in turn be used to estimate and monitor $\mathrm{SO}_{2}$ and mass fluxes during periods between TM passes and ground-based measurements. Such regular measurements of lake area, $\mathrm{SO}_{2}$ and mass flux possible using TM and AVHRR are powerful tools to aid in monitoring and understanding activity at this and other volcanic systems.

We propose an approach where TM data are collected almost simultaneously with ground-based lake area and gas flux measurements during the austral summer field season. Using the TM-derived $T_{\mathrm{e}}$ and assuming that the lake is stable over 6-month long periods (Kyle et al. 1994), AVHRR data collected on a daily basis could be used to monitor and measure lake area, $\mathrm{SO}_{2}$ and mass fluxes at a high temporal resolution over the portions of the year when ground-based measurements are impossible.

\section{Prospects}

\subsection{MODIS}

The Moderate Resolution Imaging Spectrometer (MODIS), scheduled for launch in July 1999 as part of the Earth Observing System (EOS AM-1 or Terra), will offer 36 spectral channels between 0.4 and $14.4 \mu \mathrm{m}$ at varying spatial resolutions (2 channels at $250 \mathrm{~m}$ per pixel, 5 channels at $500 \mathrm{~m}$ per pixel and the remainder at $1 \mathrm{~km}$ per pixel). MODIS has a swath width of $2330 \mathrm{~km}$, and hence will sample the entire 
globe once every 1-2 days. As MODIS is carried by the polar-orbiting EOS AM-1 (Terra), which has a 10:30 am equatorial crossing time, higher latitude targets, such as Erebus, will be imaged several times per day.

Researchers at the Hawaii Institute of Geophysics and Planetology (HIGP) have developed a thermal alert algorithm that will automatically search the entire MODIS night-time data stream for hot spots. The detection algorithm uses a combination of radiance thresholds and differences from the $3.959 \mu \mathrm{m}$ (channels 21 and 22) and the $11.202 \mu \mathrm{m}$ (channel 31) or the $12.010 \mu \mathrm{m}$ (channel 32) channels to generate thermal alerts. The 12-bit radiometric accuracy in the low gain channel 22 will ensure that changes in the Erebus lava lake area of a few to tens of square metres will result in measurable changes in radiance. Each alert file will contain geographical information (pixel latitude and longitude, sensor and solar zenith and azimuth angles) as well as five detailed radiance measurements at 3.959 (channels 21 and 22), 8.55 (channel 29), 11.020 (channel 31) and 12.010 (channel 32) $\mu \mathrm{m}$. This multiple waveband data will allow multiple-component thermal analysis of the lake as demonstrated here using TM and AVHRR. Alert files only will be sent via File Transfer Protocol (FTP) from the Goddard Space Flight Center MODIS data processing facility to HIGP, where alerts will be further analysed before appearing on an Internet web site. Thus, with the MODIS thermal alert, we will be able to monitor activity at Erebus every few hours. Work has already begun to implement a daytime MODIS thermal alert algorithm, which will offer twice as many opportunities to monitor Erebus per day. Future NASA plans include the launch of the EOS PM-1 (in 2002) which will carry a second MODIS instrument and have a 1:30 pm equatorial crossing time. Thus, by 2002 , we will have the capability to measure and monitor thermal, $\mathrm{SO}_{2}$ and mass fluxes at Erebus at least once every few hours using MODIS.

\section{2. $E T M+$ and ASTER}

Beginning in 1999, the availability of the Landsat 7 ETM+ instrument as well as the Advanced Spaceborne Thermal Emission and Reflectance Radiometer (ASTER) aboard EOS AM-1 (Terra) will provide high spatial resolution (15 m pan, $30 \mathrm{~m}$ vis-SWIR, $60-90 \mathrm{~m}$ IR) imagery of global targets including Erebus. Both the Landsat 7 and ASTER Long-term Acquisition Plans (LTAP) include collecting Erebus data on a regular basis. Interest in Antarctic satellite data is particularly strong for this region among the Landsat 7 Science Team (i.e. Luke Flynn, Erebus volcanology, and Robert Bindshadler, NASA Goddard Space Flight Center, glacial movement and morphology). Landsat 7 will fly 'in formation' with EOS AM-1, which will allow us to collect an ETM+ and ASTER image within 30 minutes of one another at least once every 16 days. This will allow us to study very high temporal changes in the lava lake at high spatial resolution. As shown here, where three or more unsaturated bands of data are available, it will be possible to measure and monitor lava lake area and temperature, as well as to calculate thermal and mass fluxes.

It will also be possible to make direct measurements of $\mathrm{SO}_{2}$ flux at Erebus using ASTER. Using ASTER wavebands coincident with $\mathrm{SO}_{2}$ absorption $(8.0-9.5 \mu \mathrm{m})$ and no absorption $(9.5-12.0 \mu \mathrm{m})$, semi-automated techniques have been developed which will allow plume-wide $\mathrm{SO}_{2}$ retrieval and mapping using ASTER data (Realmuto et al. 1994, 1997). Application to airborne Thermal Infrared Multispectral Scanner (TIMS) plume data for Etna (Sicily) and $\mathrm{Pu}^{\prime} \mathrm{u}$ 'O'o (Kupaianaha, Kilauea, Hawaii) have given detailed $\mathrm{SO}_{2}$ plume maps and $\mathrm{SO}_{2}$ fluxes of $1500-1700 \mathrm{td}^{-1}$ for the 
eruptive plume at $\mathrm{Pu}^{\prime} \mathrm{u}{ }^{\prime} \mathrm{O}^{\prime} \mathrm{o}$ and $\sim 6700 \mathrm{td}^{-1}$ for the passive plume at Etna (Realmuto et al. 1994, 1997).

\subsection{ATSR and ENVISAT}

Although an image of Erebus has yet to be analysed, the Along Track Scanning Radiometer (ATSR) which is currently flown on the European Remote Sensing Satellite (ERS-1 and ERS-2) offers great potential. The ATSR has two similar wavebands to the AVHRR at 3.7 and $10.7 \mu \mathrm{m}$, plus a third waveband at $1.6 \mu \mathrm{m}$. Wooster and Rothery (1997a) have shown how the $1.6 \mu \mathrm{m}$ is a useful tool for monitoring activity at an active lava body using time series (1992-1995) data for the active lava dome at Lascar volcano (Chile). Lava flow area and thermal structure have also been estimated using ATSR 1.6 and $11 \mu \mathrm{m}$ data (Wooster and Rothery 1997b). Our analysis of hot-spots in ATSR data due to active vents at the summit of Mount Etna (Sicily) have shown that over such targets the ATSR can provide up to three wavebands of unsaturated thermal data (R. Wright, unpublished data). For Erebus, as at Etna, this will allow two- and three-component approaches to estimate lake or vent area and thermal structure, such as that given in appendix A.

Continuity of the ATSR dataset will be assured with the launch of ENVISAT in November 1999 which will carry the Advanced Along Track Scanning Radiometer (AATSR). This will acquire data at the same $1-\mathrm{km}$ resolution wavebands as the ATSR. Although the return period for a sub-satellite tack will be 35 days, by using data from different scan positions, higher temporal resolution will be possible. For Etna this has allowed 11 cloud-free night-time images over a 2.5 month period to be acquired on which activity at the summit craters can be monitored. More data would be available if day-time data were considered or during periods of finer weather. For Erebus the repeat frequency will be higher due to its location closer to the pole.

\section{Conclusions}

With the launch of the EOS, ETM+ and ENVISAT we look forward to improved multiple data-set monitoring of Erebus. Using high spatial resolution data (TM, ETM+, ASTER) we anticipate improved measurements of the lava lake area and thermal structure which, with ASTER-derived $\mathrm{SO}_{2}$ fluxes, will allow thermal and mass fluxes to be measured on a monthly basis. Low spatial resolution data acquired at a higher temporal resolution (AVHRR, MODIS, AASTR) will allow lake area, thermal, $\mathrm{SO}_{2}$ and mass fluxes to be measured and monitored on a daily basis. In cases where saturation means that assumed temperatures are required to derive such parameters, effective temperatures derived from frequent high resolution analysis may provide required inputs. We also note that raw, night-time data is essential if accurate, unambiguous measurements are to be made.

At Erebus and other volcanoes, existing and soon-to-fly thermal remote sensing instruments offer an attractive means of complementing field measurements. In some cases parameters can be measured which are difficult or impossible to obtain from the ground (e.g. feature-wide thermal structure and flux). These benefits are particularly relevant to volcanoes like Erebus where ground-based measurements are difficult, dangerous or impossible for large portions of the year (during the austral winter). Parameters, such as thermal, $\mathrm{SO}_{2}$ and mass fluxes, derived from remotely sensed data on a regular (daily to monthly) basis, when used alongside ground-based measurements and analysis, will contribute to (1) understanding how the Erebus 
system works and impacts on the polar environment, and (2) identifying variations in activity and assessing the implications of such variations.

\section{Acknowledgments}

A.J.L.H. is funded jointly by a Leverhulme Trust Special Research Fellowship and the Open University Research Development fund. Funding for L.P.F. and TM images was provided by NASA Grant 5-3451 for the Landsat 7 Science Team.

\section{Appendix A. Solution of the three component three band equations}

We solve equations ( $3 a)$ to ( $3 b$ ) using:

$$
\begin{aligned}
& p_{\mathrm{h} 7}=\left[C_{7}-\left(C_{6} A_{7}\right) / A_{6}\right] /\left\{B_{7}-\left[\left(\mathrm{B}_{6} / \mathrm{A}_{6}\right) \mathrm{A}_{7}\right]\right\} \\
& p_{h 5}=\left[C_{5}-\left(C_{6} A_{5}\right) / A_{6}\right] /\left\{B_{5}-\left[\left(B_{6} / A_{6}\right) A_{5}\right]\right\}
\end{aligned}
$$

in which $p_{\mathrm{h} 7}$ and $p_{\mathrm{h} 5}$ are $p_{\mathrm{h}}$ calculated in bands 7 and 5 respectively, and where for band $x(x=5$ to 7$)$,

$$
\begin{aligned}
& A_{x}=L_{x}\left(T_{\mathrm{b}}\right)-L_{x}\left(T_{\mathrm{c}}\right) \\
& B_{x}=L_{x}\left(T_{\mathrm{h}}\right)-L_{x}\left(T_{\mathrm{c}}\right)
\end{aligned}
$$

and

$$
C_{x}=R_{\mathrm{x} \text { thermal }}-L_{x}\left(T_{\mathrm{c}}\right)
$$

We then solve by iteration, varying $T_{\mathrm{c}}$ until $p_{\mathrm{h} 7}=p_{\mathrm{h} 5}$.

Note that the band 7 and 5 radiances are integrated radiances $\left(R_{\mathrm{x} \text { int }}\right)$, where the radiances of the sixteen $900 \mathrm{~m}^{2}$ band 7 and 5 pixels falling within the single $14400 \mathrm{~m}^{2}$ band 6 pixel are weighted and summed as follows:

$$
R_{\mathrm{x} \text { int }}=\sum_{i=1}^{n}\left(\frac{1}{n} R_{\mathrm{x} \text { thermal }}\right)
$$

in which $n$ is the number of smaller pixels within the single larger pixel.

\section{Appendix B. Effective radiation temperature}

Effective radiation temperature is calculated from:

$$
T_{\mathrm{e}}=\left[f_{\mathrm{h}} T_{\mathrm{h}}^{4}+\left(1-f_{\mathrm{h}}\right) T_{\mathrm{c}}^{4}\right]^{0.25}
$$

In which $f_{\mathrm{h}}$ is the fraction of the lava lake occupied by the molten component. This can be calculated from

$$
f_{\mathrm{h}}=p_{\mathrm{h}} /\left(p_{\mathrm{c}}+p_{\mathrm{h}}\right)
$$

\section{Appendix C. Calculation of lava lake thermal and mass fluxes}

Following Harris et al. (1999) the lava lake thermal and mass fluxes can be calculated using a combination of ground-and satellite-based measurements as inputs in the following equations.

C1. Radiative heat losses $\left(Q_{\mathrm{rad}}\right)$

$$
Q_{\mathrm{rad}}=\sigma \varepsilon A_{\text {lake }}\left[f_{\mathrm{h}} T_{\mathrm{h}}^{4}+\left(1-f_{\mathrm{h}}\right) T_{\mathrm{c}}^{4}\right]
$$

in which $\sigma$ and $\varepsilon$ are the Stefan Boltzmann constant and lake surface emissivity respectively. 
C2. Convective heat losses ( $\left.Q_{\text {conv }}\right)$

$$
Q_{\text {conv }}=0.14 A_{\text {lake }} \kappa_{\text {air }}\left(g \alpha_{\text {air }} \rho_{\text {air }} / \mu_{\text {air }} \beta_{\text {air }}\right)^{1 / 3}\left(T_{\mathrm{e}}-T_{\text {air }}\right)^{4 / 3}
$$

in which $\kappa_{\text {air }}, \alpha_{\text {air }}, \rho_{\text {air }}, \mu_{\text {air }}, \beta_{\text {air }}$ and $T_{\text {air }}$ are the thermal conductivity, cubic expansivity, density, viscosity, thermal expansivity and temperature of the air over the lake respectively, and $g$ is acceleration due to gravity.

C3. Heat carried by the gas phase $\left(Q_{\mathrm{gas}}\right)$

$$
Q_{\text {gas }}=F_{\text {gas }} c_{\text {gas }}\left(T_{\text {magma }}-T_{\text {air }}\right)+F_{\mathrm{H} 20} L_{\mathrm{v}}
$$

in which $F_{\text {gas }}$ is the total gas flux, $c_{\text {gas }}$ is the specific heat capacity of gas, $T_{\text {magma }}$ is the magma temperature, $F_{\mathrm{H} 20}$ is the water flux, and $L_{\mathrm{v}}$ is the latent heat of condensation.

C4. Mass flux (M)

$$
M=\left[Q_{\text {rad }}+Q_{\text {conv }}\right] /\left[C_{\mathrm{L}} \Delta \mathrm{f}+C_{\text {magma }} \Delta T_{\text {magma }}\right]
$$

in which $C_{\mathrm{L}}$ is the latent heat of crystallization, $\Delta \mathrm{f}$ is the crystallized mass fraction, $C_{\text {magma }}$ is the specific heat capacity of the magma, and $\Delta T_{\mathrm{magma}}$ is magma cooling from liquidus to lake temperature.

\section{References}

Allard, P., 1997, Endogenous magma degassing and storage at Mount Etna. Geophysical Research Letters, 24, 2219-2222.

Allard, P., Carbonnelle, J., Metrich, N., Loyer, H., and Zettwoog, P., 1994, Sulphur output and magma degassing budget of Stromboli volcano. Nature, 368, 326-330.

Anderson, A. T., 1975, Some basaltic and andesitic gases. Reviews of Geophysics Space Physics, 13, 37-55.

Andres, R. J., Rose, W. I., Kyle, P. R., deSilva, S., Francis, P., Gardeweg, M., and Moreno Roa, H., 1991, Excessive sulfur dioxide emissions from Chilean volcanoes. Journal of Volcanological and Geothermal Research, 46, 323-329.

Archambault, C., and Tanguy, J. C., 1976, Comparative temperature measurements on Mount Etna: problems and techniques. Journal of Volcanological and Geothermal Research, 1, 113-125.

CAldwell, D. A., and Kyle, P. R., 1994, Minerology and geochemistry of ejecta erupted from Mount Erebus, Antarctica, between 1972 and 1986. In Volcanological and Environmental Studies of Mount Erebus, Antarctica, Antarctic Research Series, volume 66, edited by P. Kyle (Washington, DC: AGU), pp. 147-162.

Chuna, R. L., 1994, Dispersal of volcano-derived particles from Mount Erebus in the Antarctic atmosphere. In Volcanological and Environmental Studies of Mount Erebus, Antarctica, Antarctic Research Series, volume 66, edited by P. Kyle (Washington, DC: AGU), pp. $97-102$.

Dibble, R. R., O’Brien, B., and Rowe, C. A., 1994a, The velocity structure of Mount Erebus, Antarctica, and its lava lake. In Volcanological and Environmental Studies of Mount Erebus, Antarctica, Antarctic Research Series, volume 66, edited by P. Kyle (Washington, DC: AGU), pp. 1-16.

Dibble, R. R., Kyle, P. R., and Skov, M. J., 1994b, Volcanic activity and seismicity of Mount Erebus, 1986-1994. Antarctic Journal of the United States, 29, 11-15.

DozIER, J., 1981, A method for satellite identification of surface temperature fields of subpixel resolution. Remote Sensing Environment, 11, 221-229.

Dunbar, N. W., Cashman, K. V., and Dupré, R., 1994, Crystallization processes of anorthoclase phenocrysts in the Mount Erebus magmatic system: evidence from crystal composition, crystal size distributions, and volatile contents of melt inclusions. In Volcanological and Environmental Studies of Mount Erebus, Antarctica, Antarctic Research Series, volume 66, edited by P. Kyle (Washington, DC: AGU), pp. 129-146.

FLYNN, L. P., 1992, Radiative temperature measurements of the Pu'u 'O'o-Kupaianaha 
eruption with implications for satellite remote sensing. $\mathrm{PhD}$ thesis, Department of Geology and Geophysics, University of Hawaii, USA.

Flynn, L. P., Mouginis-Mark, P. J., and Horton, K. A., 1993, Radiative temperature measurements at Kupaianaha lava lake, Kilauea Volcano, Hawaii. Journal of Geophysical Research, 98, 6461-6476.

Francis, P., Oppenheimer, C., and Stevenson, D., 1993, Endogenous growth of persistently active volcanoes. Nature, 366, 554-557.

Gerlach, T. M., 1982, Interpretation of volcanic gas data from tholeiitic and alkaline mafic magmas. Bulletin of Volcanology, 45, 235-244.

Giggenbach, W. F., Kyle, P. R., and Lyon, G. L., 1973, Present volcanic activity on Mount Erebus, Ross Island, Antarctica, Geology, 1, 135-136.

Glaze, L., Francis, P. W., and Rothery, D. A., 1989, Measuring thermal budgets of active volcanoes by satellite remote sensing. Nature, 338, 144-146.

HARris, A. J. L., 1996, Low spatial resolution thermal monitoring of volcanoes from space. PhD thesis, Department of Earth Sciences, The Open University, UK.

Harris, A. J. L., Butterworth, A. L., Carlton, R. W., Downey, I., Miller, P., Navarro, P., and Rothery, D. A., 1997, Low-cost volcano surveillance from space: case studies from Etna, Krafla, Cerro Negro, Fogo, Lascar and Erebus. Bulletin of Volcanology, 59, 49-64.

Harris, A. J. L., Flynn, L. P., Rothery, D. A., Oppenheimer, C., and Sherman, S. B., 1999, Mass flux measurements at active lava lakes: implications for magma recycling. Journal of Geophysical Research, 104, 7117-7136.

Harris, A. J. L., Rothery, D. A., Carlton, R. W., Langaas, S., and Mannstein, H., 1995, Non-zero saturation of the AVHRR thermal channels over high temperature targets: evidence from volcano data and a possible explanation. International Journal of Remote Sensing, 16, 189-196.

Harris, A. J. L., and Stevenson, D. S., 1997, Magma budgets and steady-state activity of Vulcano and Stromboli. Geophysical Research Letters, 24, 1043-1046.

Higgins, J., and Harris, A. J. L., 1997, VAST: a program to locate and analyse volcanic thermal anomalies automatically from remotely sensed data. Computers and Geosciences, 23, 627-645.

Kaminuma, K., 1994, The seismic activity of Mount Erebus in 1981-1990. In Volcanological and Environmental Studies of Mount Erebus, Antarctica, Antarctic Research Series, volume 66, edited by P. Kyle (Washington, DC: AGU), pp. 35-50.

Kazahaya, K., Shinohara, H., and Saito, G., 1994, Excessive degassing of Izu-Oshima volcano: magma convection in a conduit. Bulletin of Volcanology, 56, 207-216.

Kienle, J., Kaminuma, K., and Dibble, R. R., 1984, Seismicity of Mount Erebus and vicinity, 1983-1984. Antarctic Journal of the United States, 17, 29-31.

Kienle, J., Marshall, D. L., Estes, S. A., Dibble, R. R., Shibuya, K., and Kyle, P. R., 1982, Seismicity of Mount Erebus, 1981-1982. Antarctic Journal of the United States, 19, 29-31.

Kyle, P. R., 1977, Minerology and glass chemistry of recent volcanic ejecta from Mt. Erebus, Ross Island, Antarctica. New Zealand Journal of Geology and Geophysics, 20, 1123-1146.

Kyle, P. R., 1986, Volcanic activity of Mount Erebus, 1984-1985. Antarctic Journal of the United States, 21, 7-8.

Kyle, P. R., Meeker, K., and Finnegan, D., 1990, Emission rates of sulfur dioxide, trace gases and metals from Mount Erebus, Antarctica. Geophysical Research Letters, 17, 2125-2128.

Kyle, P. R., Sybeldon, L. M., McIntosh, W. C., Meeker, K., and Symonds, R., 1994, Sulfur dioxide emission rates from Mount Erebus, Antarctica. In Volcanological and Environmental Studies of Mount Erebus, Antarctica, Antarctic Research Series, volume 66, edited by P. Kyle (Washington, DC: AGU), pp. 69-82.

McClelland, L., Simkin, T., Summers, M., Nielsen, E., and Stein, T. C., 1989, Global Volcanism 1975-1985 (New Jersey: Prentice Hall).

Oppenheimer, C., and Francis, P., 1997, Remote sensing of heat, lava and fumarole emissions from Erta 'Ale volcano, Ethiopia. International Journal of Remote Sensing, 18, $1661-1692$. 
Oppenheimer, C., Francis, P. W., Rothery, D. A., Carlton, R. W. T., and Glaze, L. S., 1993, Infrared image analysis of volcanic thermal features: Lascar volcano, Chile, 1984-1992. Journal of Geophysical Research, 98, 4269-4286.

Otway, P. M., Blick, G. H., and Scott, B. J., 1994, Volcanic deformation monitoring on Mount Erebus: methods and results of geodetic surveys, 1980-1985. In Volcanological and Environmental Studies of Mount Erebus, Antarctica, Antarctic Research Series, volume 66, edited by P. Kyle (Washington, DC: AGU), pp. 57-68.

Palais, J. M., Mosher, B. W., and Lowenthal, D., 1994, Elemental tracers of volcanic emissions from Mount Erebus in Antarctic snow samples. In Volcanological and Environmental Studies of Mount Erebus, Antarctica, Antarctic Research Series, volume 66, edited by P. Kyle (Washington, DC: AGU), pp. 103-113.

Realmuto, V. J., Abrams, M. J., Buongiorno, M. F., and Pieri, D. C., 1994, The use of multispectral thermal infrared image data to estimate the sulfur dioxide flux from volcanoes: A case study from Mount Etna, Sicily, July 29, 1986. Journal of Geophysical Research, 99, 481-488.

Realmuto, V. J., Sutton, A. J., and Elias, T., 1997, Multispectral thermal infrared mapping of sulfur dioxide plumes: A case study from the East Rift Zone of Kilauea Volcano, Hawaii. Journal of Geophysical Research, 102, 15057-15072.

Rose, W. I., Chuan, R. L., and Kyle, P. R., 1985, Rate of sulphur dioxide emission from Erebus volcano, Antarctica, December 1983. Nature, 316, 710-712.

Rothery, D. A., and Francis, P. W., 1990, Short wavelength infrared images for volcano monitoring. International Journal of Remote Sensing, 11, 1665-1667.

Rothery, D. A., Francis, P. W., and Wood, C. A., 1988, Volcano monitoring using short wavelength infrared data from satellites. Journal of Geophysical Research, 93, 7993-8008.

Rothery, D. A., and Oppenheimer, C., 1994, Monitoring Mount Erebus by satellite remote sensing. In Volcanological and Environmental Studies of Mount Erebus, Antarctica, Antarctic Research Series, volume 66, edited by P. Kyle (Washington, DC: AGU), pp. 51-56.

Rowe, C. A., and KIENLE, J., 1986, Continued surveillance of volcanic activity and seismicity of Mount Erebus, 1985-1986. Antarctic Journal of the United States, 21, 4-7.

Sheppard, D. S., Le Guern, F., and Christenson, B. W., 1994, Compositions and mass fluxes of the Mount Erebus volcanic plume. In Volcanological and Environmental Studies of Mount Erebus, Antarctica, Antarctic Research Series, volume 66, edited by P. Kyle (Washington, DC: AGU), pp. 83-96.

Wiesnet, D. R., and D'Aguanno, J., 1982, Thermal imagery of Mount Erebus from the NOAA-6 satellite. Antarctic Journal of the United States, 17, 32-34.

Wooster, M. J., and Rothery, D. A., 1997a, Thermal monitoring of Lascar volcano, Chile, using infrared data from the along-track scanning radiometer: a 1992-1995 time series. Bulletin of Volcanology, 58, 566-579.

Wooster, M. J., and Rothery, D. A., 1997b, Time-series analysis of effusive volcanic activity using the ERS Along Track Scanning Radiometer: The 1995 eruption of Fernandina Volcano, Galapagos Islands. Remote Sensing Evironment, 62, 109-117.

Zreda-Gostynska, G., Kyle, P. R., Finnegan, D., and Meeker Prestbo, K. M., 1997, Volcanic gas emissions from Mount Erebus and their impact on the Antarctic environment. Journal of Geophysical Research, 102, 15039-15055. 